American Journal of Engineering and Applied Sciences, 2012, 5 (2), 98-106

ISSN: 1941-7020

(C) 2014 Y. Zhang et al., This open access article is distributed under a Creative Commons Attribution

(CC-BY) 3.0 license

doi:10.3844/ajeassp.2012.98.106 Published Online 5 (2) 2012 (http://www.thescipub.com/ajeas.toc)

\title{
Physical Properties of Wheat Straw Varieties Cultivated Under Different Climatic and Soil Conditions in Three Continents
}

\author{
${ }^{1,2}$ Yaning Zhang, ${ }^{1}$ A.E. Ghaly and ${ }^{2}$ Bingxi Li \\ ${ }^{1}$ Department of Process Engineering and Applied Science, Faculty of Engineering, \\ Dalhousie University, Halifax, Canada \\ ${ }^{2}$ School of Energy Science and Engineering, Harbin Institute of Technology, Harbin, China
}

Received 2012-03-22; Revised 2012-06-26; Accepted 2012-06-26

\begin{abstract}
Over 500 million tonnes of wheat straw are produced annually worldwide, the majority of which are burnt in the field causing significant environmental and health problems as well as serious traffic accidents in addition to loss of a valuable resource. Wheat straw is abundantly available and renewable and can be used as an energy source in gasification and combustion systems. Proper understanding of the physical properties of wheat straw is necessary for utilizing these materials in thermochemical conversion processes. Wheat straws were collected from Egypt (Africa), Canada (North America) and Guyana (South America) and ground using medium size Wiley Mill. The physical properties (moisture content, particle size, bulk density and porosity) of wheat straws were determined using standard procedures. The moisture contents of wheat straws were in the range of 5.02-7.79\%. The majority (56.87-93.36\%) of the wheat straws particles were less than $0.85 \mathrm{~mm}$ and the average particle sizes were in the range of $0.38-0.69 \mathrm{~mm}$. The average bulk density of the wheat straws were in the range of $97.52-177.23 \mathrm{~kg} \mathrm{~m}^{-3}$. A negative linear relationship between the bulk density and the average particle size was observed for the wheat straws. The average porosity of the wheat straws were in the range of $46.39-84.24 \%$. A positive linear relationship between the porosity and the average particle size for the wheat straws was also observed. The wheat straw varieties collected from different countries had different physical properties due to variations in climatic conditions, soil type and used fertilizer. Also, significant differences were observed among the varieties grown under same climatic and cultivation conditions.
\end{abstract}

Keywords: Bulk Density, Particle Size, Moisture Content, Physical Property, Climatic Condition, Variety, Wheat Straw, Porosity

\section{INTRODUCTION}

Wheat is a staple food for 2.45 billion people ( 35 percent of the world's population) and about 30 million people are engaged in wheat cultivation (Lumpkin, 2011). The world population increased from 6.16 to 6.92 billion $(12.34 \%$ increase) during the period of 2001-2011 (USCB, 2012) and although the global wheat production fluctuated during the same period and lacked behind the population growth, it increased from 589.3 to 694.5 million tonnes $(17.84 \%$ increase) as shown in Fig. 1 (FAO, 2011). The estimated value of wheat was US\$ 208 billion in 2011. Table 1 shows the wheat production of the important wheat producing countries. Canada, Egypt and Guyana (countries used in this study) ranked $6^{\text {th }}, 13^{\text {th }}$ and $100^{\text {th }}$ of the global production, respectively. The European countries (27 countries) produce 137.49 million tonnes of wheat collectively which is $16.59 \%$ higher than that produced by China. The per capita wheat production, wheat consumption and wheat exports of the top 10 counties are presented in Fig. 2-4, respectively.

For every $1.3 \mathrm{~kg}$ of wheat grain produced, about 1 $\mathrm{kg}$ of straw is produced (Ruiz et al., 2012). This resulted in about 534.23 million tonnes of wheat straw in 2011 . Wheat straw is abundantly available and renewable and is 
currently used in some limited applications including feed stuff (Shrivastava et al., 2012), fertilizer (Xie et al., 2011), pulp and paper (Hedjazi et al., 2009), nano-materials (Chen et al., 2010) and bioethanol (Talebnia et al., 2010). However, most of the straws are burnt in the field which causes significant environmental and health problems as well as traffic accidents in addition to loss of a valuable resource (Mittal et al., 2009; Yang et al., 2008). Wheat straw is an important energy source and can be used in thermochemical conversion processes such as pyrolysis (Wild et al., 2012; Yang et al., 2010), combustion (Wang et al., 2009; Olsson, 2006) and gasification (Zhu et al., 2008; Ren et al., 2010).

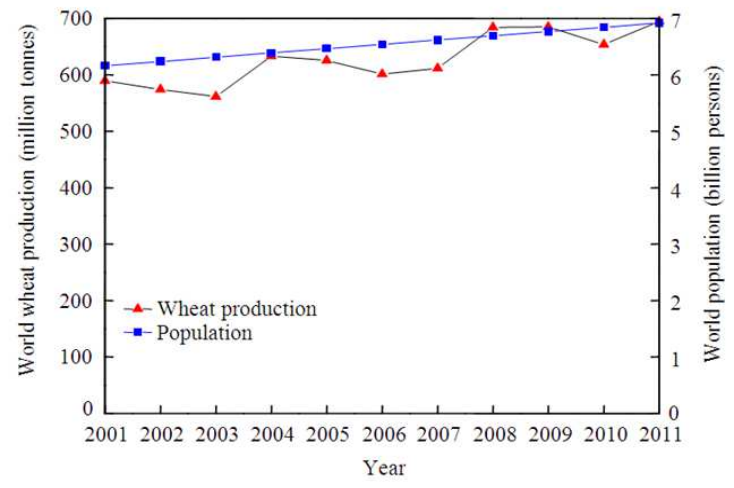

Fig. 1. World population and wheat production (FAO, 2011; USCB, 2012)

Table 1. Word wheat production (FAO, 2011; USDA, 2011; GS, 2011)

\begin{tabular}{|c|c|c|c|c|}
\hline \multirow[b]{2}{*}{ Country } & \multicolumn{4}{|c|}{ Wheat production } \\
\hline & $\begin{array}{l}\text { Weight } \\
\text { (million } \\
\text { tonnes) }\end{array}$ & $(\%)^{a}$ & $\begin{array}{l}\text { Yield } \\
\text { (tonnes } \\
\mathrm{ha}^{-1} \text { ) }\end{array}$ & $\begin{array}{l}\text { Per capita } \\
\text { (tonnes } \\
\text { person }^{-1} \text { ) }\end{array}$ \\
\hline China & 117.92 & 16.98 & 4.87 & 0.088 \\
\hline India & 85.93 & 12.37 & 2.92 & 0.069 \\
\hline Russian Federation & 56.23 & 8.10 & 2.19 & 0.394 \\
\hline United States & 54.41 & 7.83 & 2.94 & 0.174 \\
\hline Australia & 28.30 & 4.07 & 2.01 & 1.252 \\
\hline Canada & 25.26 & 3.64 & 2.96 & 0.735 \\
\hline Pakistan & 24.00 & 3.46 & 2.67 & 0.136 \\
\hline Kazakhstan & 22.50 & 3.24 & 1.63 & 1.388 \\
\hline Ukraine & 22.00 & 3.17 & 3.28 & 0.487 \\
\hline Turkey & 18.80 & 2.71 & 2.44 & 0.255 \\
\hline Argentina & 14.50 & 2.09 & 2.90 & 0.356 \\
\hline Iran & 13.75 & 1.98 & 2.02 & 0.184 \\
\hline Egypt & 8.70 & 1.25 & 6.59 & 0.105 \\
\hline Uzbekistan & 6.30 & 0.91 & 4.50 & 0.227 \\
\hline Brazil & 5.80 & 0.84 & 2.67 & 0.029 \\
\hline Morocco & 5.80 & 0.84 & 1.91 & 0.180 \\
\hline Mexico & 3.78 & 0.54 & 5.35 & 0.033 \\
\hline Syrian Arab Republic & 3.25 & 0.47 & 2.17 & 0.157 \\
\hline Algeria & 2.80 & 0.40 & 1.40 & 0.078 \\
\hline EU-27 & 137.49 & 19.80 & 5.34 & 0.274 \\
\hline Other countries & 36.99 & 5.31 & - & - \\
\hline
\end{tabular}

${ }^{\text {a }}$ Percentage of world production.

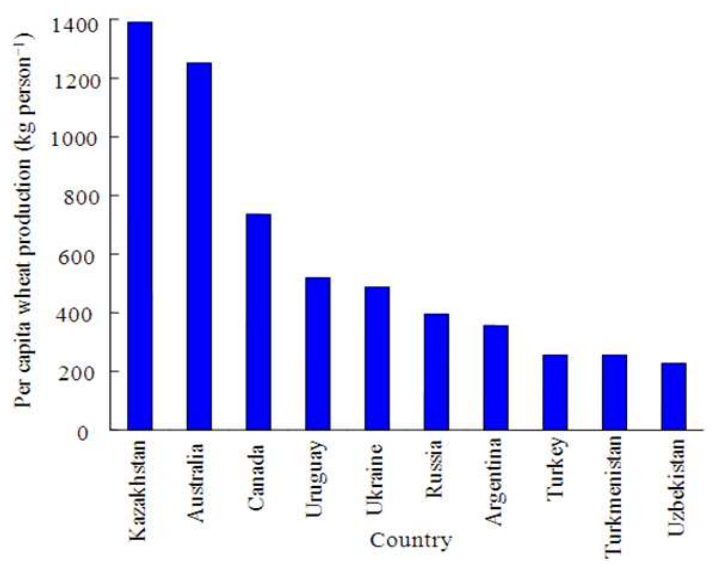

Fig. 2. Per capita wheat production of the top 10 countries (USDA, 2011; GS, 2011).

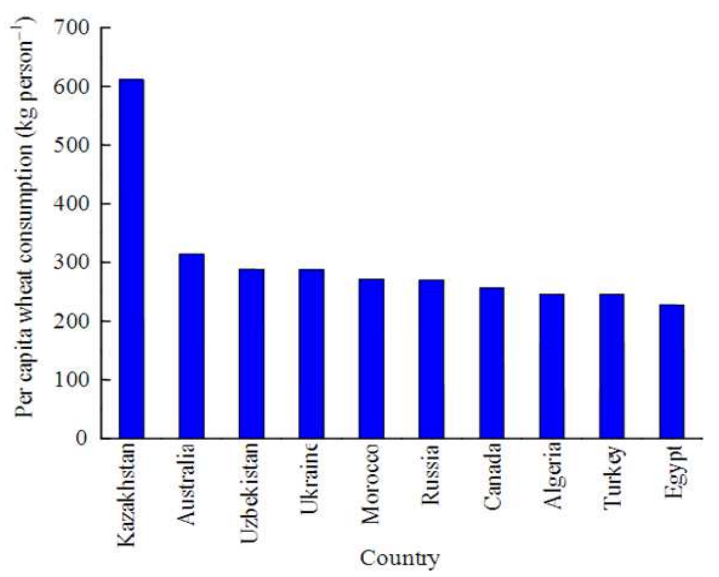

Fig. 3. Per capita wheat consumption of the top 10 countries (USDA, 2011; GS, 2011).

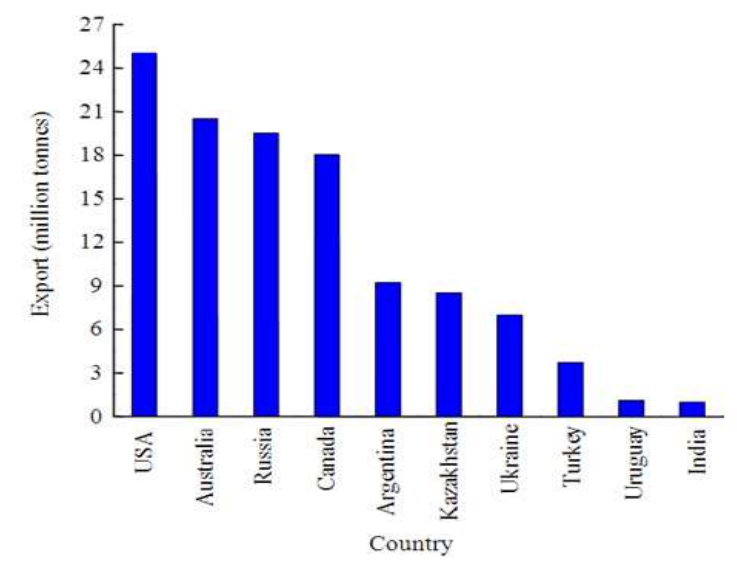

Fig. 4. Wheat exports by the top 10 countries (USDA, 2011). 
The physical properties (moisture content, particle size, bulk density and porosity) of a given biomass material such as wheat straw greatly influence the design and operation of thermochemical conversion systems. High moisture content decreases the heating value of fuel, which in turn reduces the conversion efficiency as a large amount of energy would be used for the initial drying step during the conversion processes (Mansaray and Ghaly, 1997). The particle size distribution affects the flowability, heating, diffusion and rate of reaction (Guo et al., 2012; Hernández et al., 2010). The bulk density affects the economics of collection, transportation and storage as well as feeding the material into the thermochemical conversion system (Natarajan et al., 1998). Porosity affects the interstitial airflow velocity and the heat and mass transfer conditions and ultimately influences combustion parameters such as heat conductivity, burning rate, conversion efficiency and emissions (Igathinathane et al., 2010; Hamel and Krumm, 2008). Therefore, full understanding of the physical properties of wheat straw is essential for the design and operation of efficient thermochemical conversion systems such as gasifiers and combustors.

The main objectives of this study were: (a) to investigate the physical properties (moisture content, particle size distribution, bulk density and porosity) of wheat straws obtained from three different continents (Africa, North America and South America) as related to pre-processing and the design of thermochemical conversion systems and (b) to determine the effect of wheat variety and climatic and cultivation conditions on the physical properties of wheat straws obtained from different countries (Egypt, Canada and Guyana) in these continents.

\section{MATERIALS AND METHODS}

\subsection{Sample Collection}

Six wheat straws were collected from different continents and used in this study. Giza and Sakha wheat straws were obtained from Egypt (Africa). Max and Monopol wheat straws were obtained from Canada (North America). Atlanta and Valcha wheat straws were obtained from Guyana (South America). The wheat production, climatic and soil conditions for Egypt, Canada and Guyana are shown in Table 2.

\subsection{Sample Preparation}

Wheat straw samples were ground through a coarse sieve $(12.7 \mathrm{~mm})$ and a 20 -mesh sieve $(0.85 \mathrm{~mm})$ on a medium size Wiley Mill (Model X876249, Brook Crompton Parkinson Limited, Toronto, Ontario). The coarse ground samples were then reground through a 40 -mesh sieve $(0.425 \mathrm{~mm})$ on the Wiley Mill in order to narrow the range of particle size and thus obtain homogeneous samples.

\subsection{Moisture Content}

Moisture content was determined using the oven-drying method (ASTM 2010). A large aluminum dish was weighed using a digital balance (Model PM 4600, Mettler Instrument AG, Greifensee, Zurich). The ground sample was placed in the dish and the dish and sample were weighed. The dish and sample were then placed in an air-forced drying oven (Heratherm, Thermo Fisher Scientific Inc., Waltham, USA) and kept at $105^{\circ} \mathrm{C}$ until a constant weight was achieved. The dish containing the dried sample was cooled to the room temperature in a desiccator and then weighed. The moisture content was calculated on a wet basis as follows:

$\mathrm{MC}=\frac{\mathrm{WW}-\mathrm{DW}}{\mathrm{WW}} \times 100$

where:

$\mathrm{MC}=$ The moisture content $(\mathbf{\%})$

$\mathrm{WW}=$ The wet weight of the sample and dish $(\mathrm{g})$

DW $=$ The dry weight of the sample and dish $(\mathrm{g})$

\subsection{Particle Size Distribution}

The particle size distribution was determined using seven standard sieves (Canadian Standard Sieve Series, W.S. Tyler Company of Canada Limited, St. Catharines, Ontario) and a bottom pan that collects everything that passed though the seventh sieve. The sieves were mounted on an electrical sieve shaker driven by a 0.25 -hp electric motor running at $1725 \mathrm{rpm}$ (Model Rx-86, Hoskin Scientific Limited, Gastonia, North Carolina). The sample was placed in sieve 1 , which was then covered with the sieve lid. The shaker was operated at the speed of $350 \mathrm{rpm}$ for $30 \mathrm{~min}$. The particles collected in each sieve were weighed. The sieve number, mesh number and mesh size of the seven sieves are shown in Table 3.

Table 2. Wheat production, climatic, soil and cultivation conditions for Egypt, Canada and Guyana.

\begin{tabular}{|c|c|c|c|}
\hline Parameter & Egypt & Canada & Guyana \\
\hline Wheat production $^{a}$ & 8.70 & 25.26 & NA \\
\hline Wheat straw $^{\mathrm{a}}$ & 6.69 & 19.43 & NA \\
\hline Wheat yield $\left(\mathrm{t} \mathrm{ha}^{-1}\right)$ & 6.59 & 2.96 & NA \\
\hline Precip. (mm y $\left.{ }^{-1}\right)$ & 26.00 & 865.00 & 2418 \\
\hline Minimum Tem. $\left({ }^{\circ} \mathrm{C}\right)$ & 9.00 & -16.00 & 24 \\
\hline Maximum Tem. $\left({ }^{\circ} \mathrm{C}\right)$ & 35.00 & 27.00 & 32 \\
\hline Average Tem. $\left({ }^{\circ} \mathrm{C}\right)^{\mathrm{b}}$ & 23.00 & 20.00 & 28 \\
\hline Soil type & Alluvial & Podzolic & Alluvial \\
\hline Fertilizer & Ammonium & Nitrogen & Natural \\
\hline Planting time & $9-11$ & $4-5$ & $4-5$ \\
\hline Harvesting time & $4-5$ & $6-8$ & $6-7$ \\
\hline Growing duration $^{\mathrm{c}}$ & $120-140$ & $80-100$ & $80-110$ \\
\hline
\end{tabular}


Table 3. Sieve number, mesh number and mesh size.

\begin{tabular}{lll}
\hline Sieve number & Mesh number & Mesh size $(\mathrm{mm})$ \\
\hline 1 & 20 & 0.850 \\
2 & 25 & 0.710 \\
3 & 35 & 0.500 \\
4 & 40 & 0.425 \\
5 & 45 & 0.355 \\
6 & 50 & 0.300 \\
7 & 70 & 0.212 \\
Pan & - & 0.000 \\
\hline
\end{tabular}

\subsection{Bulk Density}

An empty container $(150 \mathrm{~mL})$ was weighed using a digital balance (Model PM 4600, Mettler Instrument AG, Greifensee, Zurich) to the nearest $0.0001 \mathrm{~g}$. The container was filled with the sample and the material was slightly compacted to ensure absence of large void spaces. The container and the sample were then weighed. Three replicates were carried out. The wet bulk density of the sample was calculated from the following equation:

$\rho_{\mathrm{b}}=\frac{\left(\mathrm{W}_{2}-\mathrm{W}_{1}\right)}{\mathrm{V}}$

where:

$\rho_{\mathrm{b}} \quad=$ The bulk density of the sample $\left(\mathrm{g} \mathrm{cm}^{-3}\right)$

$\mathrm{W}_{2}=$ The weight of the container and sample $(\mathrm{g})$

$\mathrm{W}_{1}=$ The weight of the container $(\mathrm{g})$

$\mathrm{V}=$ The volume of the container $\left(\mathrm{cm}^{3}\right)$

\subsection{Porosity}

The porosity of biomass was determined using the water pycnometer method. A sample of approximately $33 \mathrm{ml}$ was placed in a $100 \mathrm{~mL}$ graduated cylinder. A wire mesh screen was placed on the top of the sample to prevent material from floating once submerged in water. Distilled water was slowly poured over the sample until the water level was above the top of the sample. The cylinder was gently rocked from side to side ten times to free trapped air bubbles before recording the final water level. The amount of added water and the water level were recorded to the nearest $1 \mathrm{~mL}$. The cylinder was emptied and cleaned thoroughly after each test. Three replicates were carried out. The porosity of biomass was calculated from the following equation:

$\mathrm{P}(\%)=\frac{\mathrm{V}_{\mathrm{i}}-\mathrm{V}_{\mathrm{f}}}{\mathrm{V}_{\mathrm{s}}} \times 100$

where:

$\mathrm{P}=$ The porosity of the sample (\%)

$\mathrm{V}_{\mathrm{i}}=$ The combined volume of the sample plus added water $(\mathrm{mL})$

$\mathrm{V}_{\mathrm{f}}=$ The final total volume of the sample and added water $(\mathrm{mL})$

$\mathrm{V}_{\mathrm{s}}=$ The volume of the sample $(\mathrm{mL})$

\section{RESULTS AND DISCUSSION}

\subsection{Moisture Content}

Table 4 shows the moisture content results of the wheat straws the moisture content was $5.16 \%$ and $7.79 \%$ for the Giza and Sakha wheat straws from Egypt, 5.79\% and $5.02 \%$ for the Max and Monopol wheat straws from Canada and 5.79\% and 5.25\% for the Atlanta and Valcha wheat straws from Guyana, respectively. Giza (5.16\%) and Sakha $(7.79 \%)$ wheat straws have different moisture content even though they were obtained from the same country (Egypt) and grown and harvested under same soil and climatic conditions. Similar results were observed with the straws obtained from Canada and Guyana which emphasize the fact that different varieties had different moisture contents even if they were cultivated, collected and stored under same conditions.

The moisture content values obtained in this study $(5.02-7.79 \%)$ are higher than the value of $4.0 \%$ reported by Adapa et al. (2009) for the wheat straw from Canada, but lower than the value of $8.30 \%$ reported by Mani et al. (2006), the value of $8.52 \%$ reported by Jiménez et al. (2000) and the values of $10-13 \%$ reported by Ghaly and Al-Taweel (1990) for the wheat straws from Canada. These variations could be explained as due to storage under different conditions and the use of different techniques to determine the moisture content. The sample reported by Adapa et al. (2009) was acquired during the summer and kept for a long time, the sample reported by Mani et al. (2006) was oven-dried for 1 hour at $130^{\circ} \mathrm{C}$, the sample reported by Jiménez et al. (2000) was sun-dried, the samples reported by Ghaly and Al-Taweel (1990) were collected from the field after harvesting while the samples used in this study were oven-dried at $105^{\circ} \mathrm{C}$ for about 24 hours.

Liang et al. (2003) and Pommier et al. (2008) stated that the moisture content provides a medium for the transport of dissolved nutrients required for the metabolic and physiological activities of microorganisms in the solid fuels and an increase in moisture content will increase the biodegradation rate of organic material, resulting in the loss of solid fuels. High moisture content of wheat straw substantially affects its quality as a fuel source and decreases its heating value, which in turn reduces the conversion efficiency and performance of the system, because a large amount of energy would be used for vaporization of the fuel moisture during the conversion processes (Chen et al., 2009; Ghaly and Al-Taweel, 1990). A dry material is thus preferred for storage, gasification and combustion, although a certain amount of moisture in the fuel is beneficial for gasification (Swierczynski et al., 2007). 
Table 4. Moisture content of wheat straws.

\begin{tabular}{ll}
\hline Wheat straw & Moisture content $(\%)^{\mathrm{a}}$ \\
\hline Giza & 5.16 \\
Sakha & 7.79 \\
Max & 5.79 \\
Monopol & 5.02 \\
Atlanta & 5.79 \\
Valcha & 5.25 \\
\hline
\end{tabular}

${ }^{a}$ Average of three replicates.

Table 5. Particle size distribution of wheat straws.

\begin{tabular}{|c|c|c|c|c|c|c|}
\hline \multirow{3}{*}{$\begin{array}{l}\text { Size range } \\
(\mathrm{mm})\end{array}$} & \multicolumn{6}{|c|}{ Weight percentage $(\%)^{\mathrm{a}}$} \\
\hline & \multicolumn{2}{|l|}{ Egypt } & \multicolumn{2}{|c|}{ Canada } & \multicolumn{2}{|c|}{ Guyana } \\
\hline & 1 & 2 & 3 & 4 & 5 & 6 \\
\hline $0 \sim 0.212$ & 26.76 & 17.66 & 6.61 & 3.30 & 3.86 & 3.66 \\
\hline $0.212 \sim 0.300$ & 17.09 & 16.65 & 7.13 & 4.76 & 5.17 & 4.49 \\
\hline $0.300 \sim 0.355$ & 11.77 & 14.17 & 7.84 & 5.42 & 6.32 & 5.23 \\
\hline $0.355 \sim 0.425$ & 10.29 & 12.05 & 8.78 & 7.60 & 7.22 & 6.46 \\
\hline $0.425 \sim 0.500$ & 10.13 & 11.28 & 9.33 & 8.25 & 8.36 & 7.74 \\
\hline $0.500 \sim 0.710$ & 9.64 & 10.60 & 13.37 & 16.02 & 12.79 & 14.22 \\
\hline $0.710 \sim 0.850$ & 7.68 & 9.08 & 14.11 & 16.25 & 13.15 & 19.15 \\
\hline$>0.850$ & 6.64 & 8.51 & 32.83 & 38.40 & 43.13 & 39.05 \\
\hline
\end{tabular}

${ }^{a}$ Average of three replicates; 1, 2, 3, 4, 5 and 6 represent the Giza, Sakha, Max, Monopol, Atlanta and Valcha wheat straws, respectively.

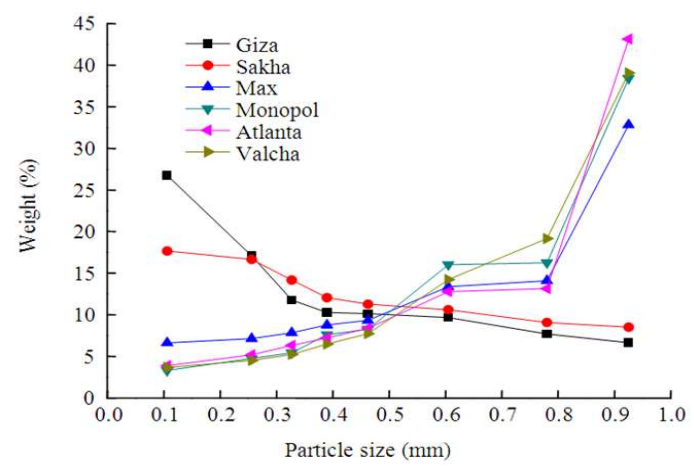

Fig. 5. Particle size distribution.

\subsection{Particle Size Distribution}

The results of the particle size distribution of wheat straws are presented in Table $\mathbf{5}$ and Fig. 5. The majority $(56.87-93.36 \%)$ of the wheat straw particles were less than $0.85 \mathrm{~mm}$. These values are within the range of $0-1.190 \mathrm{~mm}$ reported by Adapa et al. (2009) for the wheat straw from Canada. However, they are lower than the value of 3.17-12.27 mm presented by Chevanan et al. (2010) for the wheat straw from USA and higher than the value of $0-0.1 \mathrm{~mm}$ reported by Lequart et al. (2000) for the wheat straw from France. These differences could be the result of using different grinding procedures and different sieves. The sample presented by Chevanan et al. (2010) was chopped in a knife mill, the sample reported by Lequart et al. (2000) was processed by a rotative knife mill and then homogenized by a short ball milling whereas the samples in this study were ground through 3 sieves: a coarse sieve $(12.7 \mathrm{~mm})$, a 20 -mesh sieve $(0.85 \mathrm{~mm})$ and a $40-\mathrm{mesh}$ sieve $(0.425 \mathrm{~mm})$.

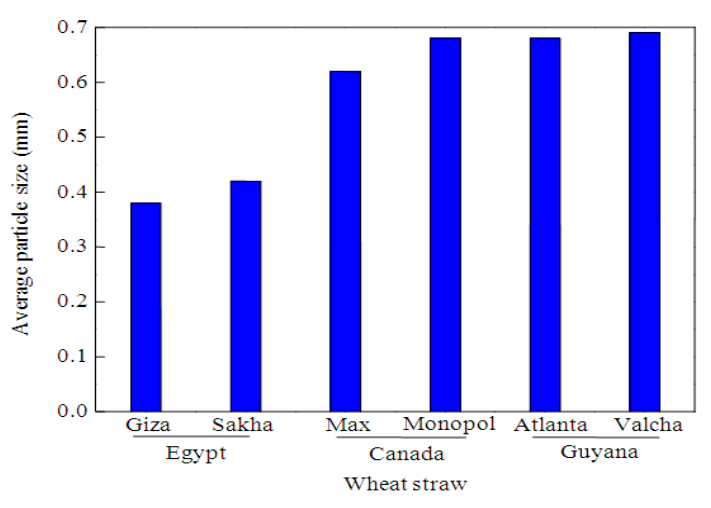

Fig. 6. Average particle size.

Figure 6 shows the average particle size of the wheat straws. The average particle sizes for Giza, Sakha, Max, Monopol, Atlanta and Valcha wheat straws were 0.38 $\mathrm{mm}, 0.42,0.62,0.68,0.68$ and $0.69 \mathrm{~mm}$, respectively. The Egyptian varieties had more fine particles than the Canadian and Guyanese varieties. The results showed that the varieties grown under the same climatic, soil and cultivation conditions had different particle size distribution and different average particle size as a result of differences in the climatic, soil and cultivation conditions of the three countries used in this study.

The average particle sizes $(0.38-0.69 \mathrm{~mm})$ of the wheat straws observed in this study are similar to the value of $0.398 \mathrm{~mm}$ reported by Adapa et al. (2009) and the values of $0.281-0.639 \mathrm{~mm}$ reported by Mani et al. (2006). They are within the range of $0.325-1.350 \mathrm{~mm}$ presented by Mani et al. (2010) and lower than the values of 1.33-1.37 mm reported by Shaw et al. (2009) for the wheat straws from Canada. These variations could be explained as due to the use of different grinding and pretreatment techniques. The samples in this study were ground through $12.7,0.85$ and $0.425 \mathrm{~mm}$ sieves, whereas the samples reported by Mani et al. (2006) were milled through 3.2, 1.6 and $0.8 \mathrm{~mm}$ sieves, the samples reported by Shaw et al. (2009) were pretreated under steam autohydrolysis at $200^{\circ} \mathrm{C}$ and $1.45-1.50 \mathrm{MPa}$ for $4 \mathrm{~min}$.

Ryu et al. (2006) stated that large particles are thermally thick thereby having slow devolatilization rate and more distributed heat transfer to nearby particles. On the other hand, small particles of fuel may enhance the reaction area and result in high burning rates and ignition front speeds (Kwong et al., 2007). Small particle size can also significantly increase the bulk density of biofuels and eventually increase the energy density and reduce the cost of transport and storage (Sangnark and Noomhorm, 2004; Chiueh et al., 2012; Deng et al., 2009). Size reduction therefore appears to be beneficial and important for pretreatment of biofuels before the utilization (Zhang and Zhang, 1999). 
Table 6. Bulk density of wheat straws.

\begin{tabular}{lc}
\hline Wheat straw & Bulk density $\left(\mathrm{kg} \mathrm{m}^{-3}\right)^{\mathrm{a}}$ \\
\hline Giza & 177.23 \\
Sakha & 160.75 \\
Max & 108.66 \\
Monopol & 99.04 \\
Atlanta & 98.82 \\
Valcha & 97.52 \\
\hline
\end{tabular}

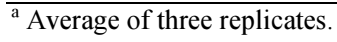

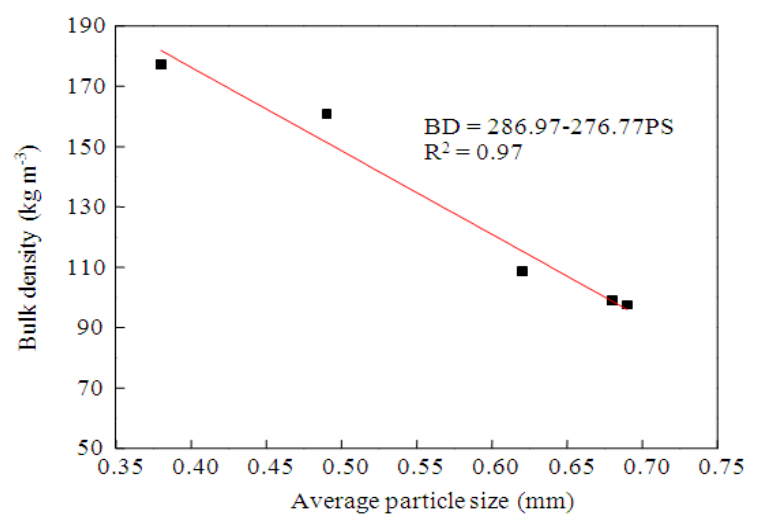

Fig. 7. Relationship between bulk density and average particle size.

\subsection{Bulk Density}

Table 6 shows the bulk density of the wheat straws. The average bulk density was $177.23 \mathrm{~kg} \mathrm{~m}^{-3}, 160.75 \mathrm{~kg}$ $\mathrm{m}^{-3}, 108.66 \mathrm{~kg} \mathrm{~m}^{-3}, 99.04 \mathrm{~kg} \mathrm{~m}^{-3}, 98.82 \mathrm{~kg} \mathrm{~m}^{-3}$ and 97.52 $\mathrm{kg} \mathrm{m}{ }^{-3}$ for Giza, Sakha, Max, Monopol, Atlanta and Valcha wheat straws, respectively. These values (97.52-177.23 $\mathrm{kg} \mathrm{m}^{-3}$ ) are similar to the values of $97.37-121.29 \mathrm{~kg} \mathrm{~m}^{-3}$ reported by Mani et al. (2006) and the values of $88-117.57 \mathrm{~kg} \mathrm{~m}^{-3}$ reported by Shaw et al. (2009) for the wheat straws from Canada. However, they are higher than the values of $25.06-62.75 \mathrm{~kg} \mathrm{~m}^{-3}$ presented by Chevanan et al. (2010) for the wheat straw from USA and lower than the value of $269 \mathrm{~kg} \mathrm{~m}^{-3}$ reported by Adapa et al. (2009) for the wheat straw from Canada. These differences could be the result of using different grinding procedures and equipment. The samples reported by Chevanan et al. (2010) were chopped in a knife mill, the samples reported by Adapa et al. (2009) were chopped using a pair of scissors and then subsequently ground using a forage grinder, whereas the samples in this study were ground in a Hammer mill (12.7, 0.85 and $0.425 \mathrm{~mm}$ ).

In this study, a negative linear relationship between the bulk density and the average particle size was observed (Fig. 7), the larger the particle size the more void will be in the material and the lower the bulk density. This relationship can be described by the following equation:

$$
\mathrm{BD}=286.97-276.77 \mathrm{PS}\left(\mathrm{R}^{2}=0.97\right)
$$

where:

$\mathrm{BD}=$ The bulk density $\left(\mathrm{kg} \mathrm{m}^{-3}\right)$

PS $=$ The average particle size $(\mathrm{mm})$

Rozainee et al. (2008) stated that the bulk density of fuel affects its residence time in the reactor. Lower bulk density may result in lower conversion efficiency, as it gives rise to poor mixing characteristics and a nonuniform temperature distribution, both of which create unfavorable operating conditions of the thermochemical conversion systems. Densification of wheat straw by pelletizing can increase its density to more than $600 \mathrm{~kg} \mathrm{~m}^{-3}$ (Theerarattananoon et al., 2011) and compaction of wheat straw can increase its density to $813-931 \mathrm{~kg} \mathrm{~m}^{-3}$ (Adapa et al., 2009). The major advantages of this technique include high volumetric density and energy content, lower transportation and storage costs and lower emissions during combustion (Ryu et al., 2006; Mani et al., 2006; Khan et al., 2009). The high investment on equipment and energy input required for pelletization and compaction are the major constrains of the densification process (Adapa et al., 2009). However, the high cost of oil, current demand for biomass utilization and technology improvement will make the processes of densification and compaction more attractive.

\subsection{Porosity}

Table 7 shows the porosity results of the wheat straws. The average porosity was $46.39,51.25,75.65$, $82.89,83.00$ and $84.24 \%$ for Giza, Sakha, Max, Monopol, Atlanta and Valcha wheat straws, respectively. The results indicate that different wheat straws obtained from different countries have different porosities. Also, the varieties grown under the same soil and climatic conditions have different porosities.

The porosity values (46.39-84.24\%) obtained in this study are slightly higher than the values of $25.06-62.75 \%$ presented by Chevanan et al. (2010) for the wheat straw from USA and similar to the value of $83.03 \%$ (calculated from the bulk density and particle density of wheat straw) reported by Adapa et al. (2009) for the wheat straw from Canada. They are, however, lower than the values of $87.86-93.30 \%$ (non-treated) and $92.75-96.34 \%$ (steam exploded) reported by Adapa et al. (2011) for the wheat straw from Canada, the values of $90.52-91.52 \%$ reported by Mani et al. (2006) and the values of $91.50-92.81 \%$ reported by Shaw et al. (2009) for the wheat straws from Canada and the value of $96.97 \%$ presented by Biricik et al. (1999) for the wheat straw from Turkey. These variations may also be due to the use of different grinding procedures, pretreatment techniques and wheat straw variety. 
Table 7. Porosity of wheat straws.

\begin{tabular}{ll}
\hline Wheat straw & Porosity $(\%)^{\mathrm{a}}$ \\
\hline Giza & 46.39 \\
Sakha & 51.25 \\
Max & 75.65 \\
Monopol & 82.89 \\
Atlanta & 83.00 \\
Valcha & 84.24
\end{tabular}

${ }^{\mathrm{a}}$ Average of three replicates.

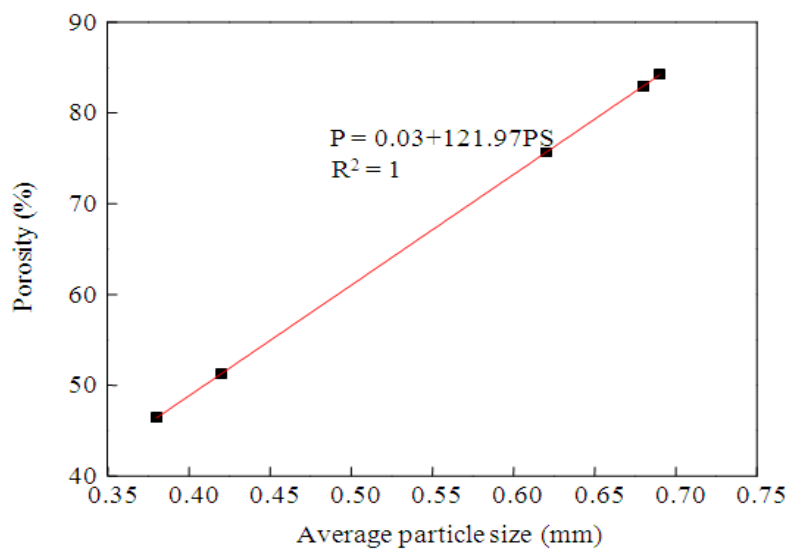

Fig. 8. Relationship between porosity and average particle size.

Igathinathane et al. (2010) stated that the porosity of biomass samples depends on a number of factors including particle size distribution, particle shape, shaking and pressing. Differences in average particle size can result from using different procedures and will significantly affect the porosity. A positive linear relationship between the porosity and the average particle size for the wheat straws is observed in this study and is shown in Fig. 8, the smaller the particle size the lower the porosity of the material. The relationship can be described by the following equation:

$$
\mathrm{P}=121.97 \mathrm{PS}\left(\mathrm{R}^{2}=1.00\right)
$$

where:

$\mathrm{P}=$ The porosity $(\%)$

A decrease in the porosity will increase the interstitial airflow velocity and brings changes in heat and mass transfer conditions and ultimately influences the combustion parameters such as heat conductivity, burning rate, conversion efficiency and emissions (Igathinathane et al., 2010; Hamel and Krumm, 2008). Pelletizing or compacting can decrease the porosity of biomass samples. However, these dense materials may deteriorate the flow characteristics in the gasifier or combustor, thereby causing post-processing problems (Chen et al., 2009).

\subsection{Effects of Variety and Climatic and Cultivation Conditions}

The results obtained from this study showed significant differences in the physical properties of the wheat straws collected from different countries (Egypt, Canada and Guyana) located in three different continents (Africa, North America and South America). These may be due to variations in climatic conditions (temperature, precipitation and length of cultivation season) and cultivation conditions (soil type and used fertilizer) as shown in Table 2. Also, significant differences were observed among the varieties grown under same climatic and cultivation conditions.

\section{CONCLUSION}

The physical properties of wheat straws obtained from three countries Egypt (Africa), Canada (North America) and Guyana (South America) were determined. These included moisture content, particle size distribution, bulk density and porosity. The moisture contents of wheat straws were in the range of $5.02-7.79 \%$. The majority $(56.87-93.36 \%)$ of the wheat straw particles were less than $0.85 \mathrm{~mm}$ and the average particle sizes were in the range of $0.38-0.69 \mathrm{~mm}$. The bulk density of the wheat straws was in the range of 97.52-177.23 $\mathrm{kg} \mathrm{m}^{-3}$. A negative linear relationship between the bulk density and the average particle size was observed. The porosity of the wheat straws was in the range of $46.39-84.24 \%$. A positive linear relationship between the porosity and the average particle size was observed. The results obtained from this study indicate that the wheat straw varieties collected from different countries located in different continents have different physical properties due to variations in climatic conditions, soil type and fertilizer used. Also, significant differences were observed among varieties grown under same climatic and cultivation conditions.

\section{ACKNOWLEDGEMENT}

The project was funded by National Science and Engineering Council (NSERC) of Canada. The authors would like to thank Mr. Rye Dube and Mr. Weida Shi for their technical support during the grinding experiments.

\section{REFERENCES}

Adapa, P., L. Tabil and G. Schoenau, 2009. Compaction characteristics of barley, canola, oat and wheat straw. Biosyst. Eng., 104: 335-344. DOI: 10.1016/j.biosystemseng.2009.06.022

Adapa, P., L. Tabil and G. Schoenau, 2011. Grinding performance and physical properties of non-treated and steam exploded barley, canola, oat and wheat straw. Biomass Bioenergy, 35: 549-561. DOI: 10.1016/j.biombioe.2010.10.004 
Biricik, H., F. Akoz, I.I. Berktay and A.N. Tulgar, 1999. Study of pozzolanic properties of wheat straw ash. Cement Concrete Res., 29: 637-643. DOI: 10.1016/S0008-8846(98)00249-X

Chen, H., F. Wang, C. Zhang, Y. Shi and G. Jin et al., 2010. Preparation of nano-silica materials: The concept from wheat straw. J. Non-Crystalline Solids, 356: 2781-2785. DOI: 10.1016/j.jnoncrysol.2010.09.051

Chen, L., L. Xing and L. Han, 2009. Renewable energy from agro-residues in China: Solid biofuels and biomass briquetting technology. Renew. Sustain. Energy Rev., 13: 2689-2695. DOI: 10.1016/j.rser.2009.06.025

Chevanan, N., A.R. Womac, V.S.P. Bitra, C. Igathinathane and Y.T. Yang et al., 2010. Bulk density and compaction behavior of knife mill chopped switchgrass, wheat straw and corn stover. Bioresource Technol., 101: 207-214. DOI: 10.1016/j.biortech.2009.07.083

Chiueh, P.T., K.C. Lee, F.S. Syu and S.L. Lo, 2012. Implications of biomass pretreatment to cost and carbon emissions: Case study of rice straw and Pennisetum in Taiwan. Bioresou. Technol., 108: 285-294. DOI: 10.1016/j.biortech.2012.01.006

Deng, J., G.J. Wang, J.H. Kuang, Y.L. Zhang and Y.H. Luo, 2009. Pretreatment of agricultural residues for co-gasification via torrefaction. J. Analytical Applied $\begin{array}{lll}\text { Pyrolysis, } & \text { 86: 331-337. DOI: }\end{array}$ 10.1016/j.jaap.2009.08.006

FAO, 2011. FAO cereal supply and demand brief. Food and Agriculture Organization.

Ghaly, A.E. and A. Al-Taweel, 1990. Physical and thermochemical properties of cereal straws. Energy Sour., 12: 131-145. DOI: 10.1080/00908319008960195

GS, 2011. Overview of the world's nations and their population. Global Statistics.

Guo, Q., X. Chen and H. Liu, 2012. Experimental research on shape and size distribution of biomass particle. Fuel, 94: 551-555. DOI: 10.1016/j.fuel.2011.11.041

Hamel, S. and W. Krumm, 2008. Near-wall porosity characteristics of fixed beds packed with wood chips. Powder Technol., 188: 55-63. DOI: 10.1016/j.powtec.2008.03.011

Hedjazi, S., O. Kordsachia, R. Patt, A.J. Latibari and U. Tschirner, 2009. Alkaline Sulfite-Anthraquinone (AS/AQ) pulping of wheat straw and Totally Chlorine Free (TCF) bleaching of pulps. Ind. Crops Produ., 29: 27-36. DOI: 10.1016/j.indcrop.2008.03.013

Hernández, J.J., G. Aranda-Almansa and A. Bula, 2010. Gasification of biomass wastes in an entrained flow gasifier: Effect of the particle size and the residence time. Fuel Process. Technol., 91: 681-692. DOI: 10.1016/j.fuproc.2010.01.018
Igathinathane, C., J.S. Tumuluru, S. Sokhansanj, X. Bi and C.J. Lim et al., 2010. Simple and inexpensive method of wood pellets macro-porosity measurement. Bioresour. Technol., 101: 6528-6537. DOI: 10.1016/j.biortech.2010.03.034

Jiménez, L., I. Pérez, M.J.D.L. Torre, F. López, J. Ariza, 2000. Use of formaldehyde for making wheat straw cellulose pulp. Bioresour. Technol., 72: 283-288.

Khan, A.A., W. de Jong, P.J. Jansens, H. Spliethoff, 2009. Biomass combustion in fluidized bed boilers: Potential problems and remedies. Fuel Process. Technol., 90 : 21-50. DOI: 10.1016/j.fuproc.2008.07.012

Kwong, P.C.W., C.Y.H. Chao, J.H. Wang, C.W. Cheung and G. Kendall, 2007. Co-combustion performance of coal with rice husks and bamboo. Atmospheric Environ., 41: 7462-7472. DOI: 10.1016/j.atmosenv.2007.05.040

Lequart, C., K. Ruel, C. Lapierre, B. Pollet and B. Kurek. 2000. Abiotic and enzymatic degradation of wheat straw cell wall: A biochemical and ultrastructural investigation. J. Biotechnol., 80: 249-259. DOI: 10.1016/S0168-1656(00)00267-4

Liang, C., K.C. Das and R.W. McClendon. 2003. The influence of temperature and moisture contents regimes on the aerobic microbial activity of a biosolids composting blend. Bioresour. Technol., 86: 131-137. DOI: 10.1016/S0960-8524(02)00153-0

Lumpkin, T.A. 2011. Wheat-global alliance for improving food security and the livelihoods of the resource-poor in the developing world. National Agricultural Research Institute.

Mani, S., L.G. Tabil and S. Sokhansanj, 2006. Effects of compressive force, particle size and moisture content on mechanical properties of biomass pellets from grasses. Biomass Bioenergy, 30: 648-654. DOI: 10.1016/j.biombioe.2005.01.004

Mani, T., P. Murugan, J. Abedi and N. Mahinpey, 2010. Pyrolysis of wheat straw in a thermogravime-tric analyzer: Effect of particle size and heating rate on devolatilization and estimation of global kinetics. Chem. Eng. Res. Design, 88: 952-958. DOI: 10.1016/j.cherd.2010.02.008

Mansaray, K.G. and A.E. Ghaly, 1997. Physical and thermochemical properties of rice husk. Energy Sour., 19: 989-1004. DOI: 10.1080/00908319708908904

Mittal, S.K., N. Singh, R. Agarwal, A. Awasthi and P.K. Gupta, 2009. Ambient air quality during wheat and rice crop stubble burning episodes in Patiala. Atmospheric Environ., 43: 238-244. DOI: 10.1016/j.atmosenv.2008.09.068 
Natarajan, E., A. Nordin and A.N. Rao, 1998. Overview of combustion and gasification of rice husk in fluidized bed reactors. Biomass Bioenergy, 14: 533-546. DOI: 10.1016/S0961-9534(97)10060-5

Olsson, M., 2006. Wheat straw and peat for fuel pellets-organic compounds from combustion. Biomass Bioenergy, 30: 555-564. DOI: 10.1016/j.biombioe.2006.01.005

Pommier, S., D. Chenu, M. Quintard and X. Lefebvre, 2008. Modelling of moisture-dependent aerobic degradation of solid waste. Waste Manage., 28: 1188-1200. DOI: 10.1016/j.wasman.2007.05.002

Ren, Q., C. Zhao, X. Wu, C. Liang and X. Chen et al., 2010. Formation of $\mathrm{NO}_{\mathrm{x}}$ precursors during wheat straw pyrolysis and gasification with $\mathrm{O}_{2}$ and $\mathrm{CO}_{2}$. Fuel, 89: 1064-1069. DOI: 10.1016/j.fuel.2009.12.001

Rozainee, M., S.P. Ngo, A.A. Salema, K.G. Tan and M. Ariffin et al., 2008. Effect of fluidising velocity on the combustion of rice husk in a bench-scale fluidised bed combustor for the production of amorphous rice husk ash. Bioresour. Technol., 99: 703-713. DOI: 10.1016/j.biortech.2007.01.049

Ruiz, H.A., D.P. Silva, D.S. Ruzene, L.F. Lima and A.A. Vicente et al., 2012. Bioethanol production from hydrothermal pretreated wheat straw by a flocculating Saccharomycescerevisiae strain-effect of process conditions. Fuel, 95: 528-536. DOI: 10.1016/j.fuel.2011.10.060

Ryu, C., Y.B. Yang, A. Khor, N.E. Yates and V.N. Sharifi et al., 2006. Effect of fuel properties on biomass combustion: Part I. Experiments-fuel type, equivalence ratio and particle size. Fuel, 85: 1039-1046. DOI: 10.1016/j.fuel.2005.09.019

Sangnark, A. and A. Noomhorm, 2004. Chemical, physical and baking properties of dietary fiber prepared from rice straw. Food Res. Int., 37: 66-74. DOI: 10.1016/j.foodres.2003.09.007

Shaw, M.D., C. Karunakaran and L.G. Tabil, 2009. Physicochemical characteristics of densified untreated and steam exploded poplar wood and wheat straw grinds. Biosyst. Eng., 103: 198-207. DOI: 10.1016/j.biosystemseng.2009.02.012

Shrivastava, B., P. Nandal, A. Sharma, K.K. Jain and Y.P. Khasa et al., 2012. Solid state bioconversion of wheat straw into digestible and nutritive ruminant feed by Ganoderma sp. rckk02. Bioresour. Technol., 107: 347-351. DOI: 10.1016/j.biortech.2011.12.096

Swierczynski, D., S. Libs, C. Courson and A. Kiennemann, 2007. Steam reforming of tar from a biomass gasification process over Ni/olivine catalyst using toluene as a model compound. Applied Catalysis B: Environ., $\quad 74$ : 211-222. 10.1016/j.apcatb.2007.01.017
Talebnia, F., D. Karakashev and I. Angelidaki, 2010. Production of bioethanol from wheat straw: An overview on pretreatment, hydrolysis and fermentation. Bioresour. Technol., 101: 4744-4753. DOI: 10.1016/j.biortech.2009.11.080

Theerarattananoon, K., F. Xu, J. Wilson, R. Ballard and L. Mckinney et al., 2011. Physical properties of pellets made from sorghum stalk, corn stover, wheat straw and big bluestem. Indus. Crops Produ., 33: 325-332. DOI: 10.1016/j.indcrop.2010.11.014

USCB, 2012. Source: U.S. bureau of the census, current population projections. USCB.

USDA, 2011. Wheat production by country in $1000 \mathrm{HA}$.

Wang, C., F. Wang, Q. Yang and R. Liang, 2009.

Thermogravimetric studies of the behavior of wheat straw with added coal during combustion. Biomass Bioenergy, 33: 50-56. 10.1016/j.biombioe.2008.04.013

Wild, P.J.D., W.J.J. Huijgen and H.J. Heeres, 2012. Pyrolysis of wheat straw-derived organosolv lignin. J. Analytical Applied Pyrolysis, 93: 95-103. DOI: 10.1016/j.jaap.2011.10.002

Xie, L., M. Liu, B. Ni, X. Zhang and Y. Wang, 2011. Slow-release nitrogen and boron fertilizer from a functional superabsorbent formulation based on wheat straw and attapulgite. Chem. Eng. J., 167: 342-348. DOI: 10.1016/j.cej.2010.12.082

Yang, Q., S. Wu, R. Lou and G. Lv, 2010. Analysis of wheat straw lignin by thermogravimetry and pyrolysis-gas chromatography/mass spectrometry. J. Analytical Applied Pyrolysis, 87: 65-69. DOI: 10.1016/j.jaap.2009.10.006

Yang, S., H. He, S. Lu, D. Chen and J. Zhu, 2008. Quantification of crop residue burning in the field and its influence on ambient air quality in Suqian, China. Atmospheric Environ., 42: 1961-1969. DOI: 10.1016/j.atmosenv.2007.12.007

Zhang, R. and Z. Zhang, 1999. Biogasification of rice straw with an anaerobic-phased solids digester system. Bioresour. Technol., 68: 235-245. DOI: 10.1016/S0960-8524(98)00154-0

Zhu, W., W. Song and W. Lin, 2008. Catalytic gasification of char from co-pyrolysis of coal and biomass. Fuel Process. Technol., 89: 890-896. DOI: 10.1016/j.fuproc.2008.03.00 